\title{
Effects of Fluvoxamine on Cognitive Function in Outpatients with Depression in Remission: Results of an Open-Label Pilot Study
}

\author{
Alexey Bobrov ${ }^{1,2 *}$ Larisa Krasnoslobodtseva ${ }^{2}$ and Elena Mutnykh ${ }^{2}$ \\ ${ }^{1}$ Federal Medical Research Centre for Psychiatry and Narcology, Moscow, Russia \\ ${ }^{2}$ Department of Psychiatry, Faculty of Postgraduate Education, Pirogov Russian National Research Medical University, Moscow, Russia
}

\begin{abstract}
A prospective, non-comparative, single-centre, single-group study was conducted in 50 adult patients with currently remitted recurrent depressive disorder according to the criteria of the International Classification of Diseases, 10th revision in order to assess changes in cognitive function during preventive therapy with fluvoxamine. Responses to therapy were evaluated using the Stroop Color and Word Test as the primary efficacy outcome. The revised Addenbrooke's Cognitive Examination, Frontal Assessment Battery, Hamilton Rating Scale for Depression and Social Adaptation Self-evaluation Scale were used as secondary indices. Fluvoxamine was administered at doses of 50-150 mg/day for 24 weeks. Fluvoxamine therapy was associated with a range of 'pro-cognitive' responses that resulted in improvement in executive functions, including improved voluntary regulation of inhibitory control and restoration of verbal fluency. No dose relation was apparent for these effects. The incidence of treatmentrelated adverse events was low and no serious or severe events were recorded. These findings indicate that further studies of fluvoxamine are warranted and feasible to characterize possible beneficial effects on cognitive processes in patients with depression.
\end{abstract}

Keywords: Fluvoxamine; Cognitive function; Depression; Antidepressant therapy

Abbreviations: ACE-R: Revised Addenbrooke's Cognitive Examination; ANOVA: Analysis of variance; FAB: Frontal Assessment Battery; HAM-D: Hamilton Rating Scale for Depression; MDD: Major Depressive Disorders; MDE: Major Depressive Episode; SASS: Social Adaptation Self-evaluation Scale; SD: Standard Deviation

\section{Introduction}

Impairment of cognitive function is a frequent comorbidity associated with major depressive disorders (MDD) and one of the most widely encountered residual sequelae of MDD, persisting even in remitted MDD [1-3]. The precise nature of the physiological, anatomical and functional inter-relations between depression and cognitive impairment is complex and incompletely understood at present although it is being explored in various lines of research [4-11]. Much of this research is focused on older adults but the connection between MDD and cognitive limitation is also apparent in younger adults, in whom it may have a direct negative impact on work productivity, especially in the form of 'presentee-ism' [12], and perhaps wider consequences with regard to their capacity to discharge the responsibilities of adult life as well as affecting the costs of care [13].

The impact of cognitive impairment in MDD appears to be widely appreciated in psychiatry but apparently exerts little influence with regard to the choice of antidepressant therapy [14]. Reasons for this gap between the perception of a problem and a response to it are unclear and may be multiple but one factor may be the perception of an unsatisfactory effect of antidepressant treatments on cognitive deficits for many individuals with MDD. When antidepressants are considered broadly, there are some grounds for this view [15] although there are also data to suggest that antidepressants (or remission of depression) may be associated with partial recovery of cognitive capacities. Differences between classes of antidepressants have been posited [16] and reports on bupropion [17] and vortioxetine [18] encourage the view that the pharmacodynamic profiles of individual drugs may produce clinically pertinent differences between antidepressants.

The selective serotonin reuptake inhibitor fluvoxamine is one of the most potent sigma-1 receptor agonists in its class. Sigma-1 receptor agonists demonstrate significant anti-amnestic and neuroprotective effects in various experimental models [19], and fluvoxamine has been reported to be clinically effective in some psychopathological conditions associated with cognitive impairment [20-22].

In view of the above, we designed a study of possible favourable effects of fluvoxamine on cognitive performance in patients with recurrent depression who were in a state of incomplete therapeutic remission.

\section{Materials and Methods}

This was a prospective, non-comparative, single-centre, singlegroup study designed to assess changes in cognitive function during fluvoxamine preventive therapy for remitted depression. The study population comprised adults aged 18-65 years who had been diagnosed with recurrent depressive disorder (F33) according to the International Classification of Diseases, 10th revision at least 2 years prior to the start of the study and who had experienced at least two severe depressive episodes (with or without psychotic symptoms) but were currently in remission and had been for 4 weeks to 6 months after the most recent depressive episode. Remission was defined as a score of $\leq 7$ on the Hamilton Rating Scale for Depression (HAM-D).

Other eligibility requirements included: planned prescription of fluvoxamine for preventive therapy of recurrent depressive disorder;

*Corresponding author: Alexey Bobrov, Department of Psychiatry, Faculty of Postgraduate Education, Pirogov Russian National Research Medical University Moscow, Russia, Tel +7495 9637684; Fax: +7 495 9637684; E-mail: bobrov2004@ yandex.ru

Received: July 17, 2017; Accepted: August 15, 2017; Published: August 22, 2017

Citation: Bobrov A, Krasnoslobodtseva L, Mutnykh E (2017) Effects of Fluvoxamine on Cognitive Function in Outpatients with Depression in Remission: Results of an Open-Label Pilot Study. J Psychiatry 20: 417. doi:10.4172/2378-5756.1000417

Copyright: @ 2017 Bobrov A, et al. This is an open-access article distributed under the terms of the Creative Commons Attribution License, which permits unrestricted use, distribution, and reproduction in any medium, provided the original author and source are credited 
total score of $\leq 93$ at screening on the revised Addenbrooke's Cognitive Examination (ACE-R); increase of at least $10 \%$ in the time taken to read words between the first and third parts of the Stroop Color and Word Test and/or $\geq 3$ mistakes whilst reading words on the third part of the Stroop Color and Word Test; fluency in Russian; and adequate visual, hearing and graphomotor skills to undertake cognitive testing.

Principal exclusion criteria included, but were not limited to: current depressive or manic episode, bipolar affective disorder, persistent mood affective disorder, other or unspecified mood affective disorder, substance-related disorders, schizophrenia or other psychotic disorders; history of a drug or alcohol disorder within 2 years prior to screening visit 1; active smoker; current treatment with fluvoxamine or prior therapy within 4 weeks or a history of a lack of response to a previous preventive treatment course with fluvoxamine; history of depressive disorder associated with endocrine disorders; positive pregnancy test for females of childbearing potential; breast-feeding female patients; history of any significant neurologic disease or of significant head trauma followed by persistent neurologic deficits or known structural brain abnormalities; treatment with electroconvulsive therapy in the 6 months preceding the study; use of medications known to interact with fluvoxamine, including tizanidine, monoamine oxidase inhibitors and ramelteon, or of any concomitant psychotropic medications other than the protocol-specified sedatives/hypnotics; and initiation of psychotherapy, cognitive behavioural therapy or other therapies (such as acupuncture or hypnosis) within 12 weeks prior to enrolment.

\section{Study endpoints}

The primary objective was to assess cognitive executive functions in remitted depression patients during 24 weeks of preventive treatment with fluvoxamine. Secondary objectives comprised assessment of overall cognitive functioning in remitted depression patients during preventive treatment with fluvoxamine; maintenance of remission status; routine social functioning; and any associations between cognitive functioning and routine social functioning. A series of established tests were used for this purpose.

The Stroop Color and Word Test is considered to measure selective attention, cognitive flexibility and processing speed. It is used as a tool to evaluate brain dysfunction, cognition and psychopathology and provides valuable diagnostic information on those aspects [23,24]. The Stroop Color and Word Test consists of three parts. In Part I, the participants read aloud a standard list of names of colours printed in black ink. Part II requires the participants to name the colours of blocks printed using differently coloured inks. In Part III, participants name the colours of mismatched inks in which the names of the colours are printed. The execution-time differences between Parts I and II, Parts I and III and Parts II and III are calculated.

The ACE-R contains five subscales, each of which represents one cognitive domain: attention/orientation, memory, verbal fluency, language and visuo-spatial [25]. The maximum aggregate score is 100.

The HAM-D is a clinical scale that can be used by an investigator to rate the severity of a patient's major depression [26]. A score of 0-7 is considered to be normal; scores of $\geq 20$ indicate moderately severe depression.

The Frontal Assessment Battery (FAB) assesses frontal lobe function and consists of six domains: conceptualization; mental flexibility; motor programming; sensitivity to interference; inhibitory control; and environmental autonomy [27].
The Social Adaptation Self-evaluation Scale (SASS) is a 21-item self-rating scale for the evaluation of patient social motivation and behaviour in depression [28]. Each answer is scored from zero to three, corresponding to minimal and maximal social adjustment, respectively, and the total score ranges from 0 to 60 .

Treatment effects on all these instruments were compared between baseline and 24 weeks of treatment. The prespecified primary endpoint was the change in time difference between Parts I and II, II and III, I and III of the Stroop Color and Word Test. Secondary endpoints, also assessed between baseline and Week 24, comprised changes in total FAB score; change in ACE-R general score; change in SASS total score and the proportion of patients who maintained remission.

\section{Study medication}

The study medication, fluvoxamine $\left(\right.$ Fevarin $\left.^{\circledR}\right)$, was supplied by Abbott Laboratories LLC (Moscow, Russia). Supplies were manufactured in compliance with the Good Manufacturing Practice specifications and other current regulations or local legislation.

The recommended starting dose of fluvoxamine was 50 or $100 \mathrm{mg} /$ day taken in the evening with the option, at the investigator's discretion and depending on the patient's response, of an increase to $150 \mathrm{mg} /$ day.

The maximum duration of treatment was 24 weeks, with a further 30 days of follow-up assigned for safety monitoring.

\section{Study structure, ethics and informed consent}

This was an investigator-initiated study conducted at the Moscow Research Institute of Psychiatry, a branch of the Federal Medical Research Centre for Psychiatry and Narcology. The lead investigator (A.E.B.) was responsible for quality monitoring throughout the study.

The study protocol plus all amendments were reviewed and approved by the Independent Ethics Committee and Institutional Review Board. The study was conducted in accordance with the protocol, the International Conference on Harmonization guidelines, applicable national and local regulations and guidelines governing clinical study conduct and was compatible with the ethical principles set out in the Declaration of Helsinki.

Voluntary and informed written consent was obtained from all patients prior to the start of any study procedures at the screening visit and was retained among each patient's medical records.

Data entry and data management were carried out by the authors.

\section{Statistical considerations}

Determination of sample size was based on the primary endpoint, namely the incongruent reading speed in the Stroop Color and Word Test. From our previous work [29], it is known that the standard deviation of this parameter is $5.94 \mathrm{~s}$ and that the minimum clinically significant difference in the test is 5 s. From this, specifying a significance level of $5 \%$ and a statistical power of $80 \%$ in a two-tailed test, a minimum per-protocol sample size estimate of 35 was derived. This was increased to 43 to reflect the fact that the outcome variable does not follow a normal distribution and the overall sample size for the intention-to-treat population was set to 50 subjects.

Statistical analysis was performed by A.E.B. using the Statistica 10 software package (StatSoft Russia, Moscow, Russia). Preliminary analysis showed that the Stroop Color and Word Test, ACE-R, HAM-D and SASS data approximated, but did not always follow, a normal distribution. The FAB data were not normally distributed. For this 
Citation: Bobrov A, Krasnoslobodtseva L, Mutnykh E (2017) Effects of Fluvoxamine on Cognitive Function in Outpatients with Depression in Remission: Results of an Open-Label Pilot Study. J Psychiatry 20: 417. doi:10.4172/2378-5756.1000417

Page 3 of 6

reason, non-parametric statistical methods (Wilcoxon matched-pair test, Friedman analysis of variance [ANOVA]) were mainly used for data processing

\section{Results}

\section{Demographics and general}

The planned total of 50 patients was recruited, two of whom (both men) were lost to follow-up within the first month of the study and excluded from the final analyses. The remaining 48 patients $(24$ males, 24 females) had a mean (standard deviation [SD]) age of 44.1 (11.5) years (range 21-65 years). Education levels in these 48 patients were classified as secondary education $(n=10)$, specialized secondary education $(n=8)$ and higher education $(n=30)$.

The duration of recurrent depression varied from 1 to 19 years with a mean (SD) of 9.6 (4.9) years and the number of preceding episodes of depression varied from two to seven with a mean (SD) of 3.0 (1.1). One subject $(2.1 \%)$ had one episode of depression with psychotic symptoms in the past. Ten patients had a single occurrence of in-patient treatment in their medical history. One-third of patients $(n=16)$ had concurrent somatic disorders: essential hypertension $(n=6,12.5 \%)$, gastritis $(n=7$, $14.6 \%)$, pyelonephritis $(n=4,8.3 \%)$ and chronic adnexitis $(n=1,2.1 \%)$.

Treatment compliance was evaluated at three points during the study and was considered satisfactory except for the two patients who discontinued. Between Weeks 12 and 24, 13 patients (27.1\%) received $50 \mathrm{mg} /$ day fluvoxamine, $33(68.8 \%)$ received $100 \mathrm{mg} /$ day and two (4.2\%) received $150 \mathrm{mg}$ /day. No significant influence of fluvoxamine dose on responses to outcome parameters was identified, with the possible exception of the verbal fluency domain of the ACE-R.

\section{Endpoint findings}

Fluvoxamine treatment was associated with statistically significant improvements in scores for all three parts of the Stroop Color and Word Test, as shown in (Table 1). The biggest reduction in execution time was registered for Part III naming the colour of an ink in which a mismatched name of a colour is printed. For the parameter estimates, the most significant changes were registered for time difference between Parts I and III. Statistically significant changes were also registered for time difference between Part II and Part III (the parameter representing verbal-colour interference) but not between Part I and Part II (the parameter representing so-called colour difficulty). Change in execution time median values of difference as a percentage from baseline level between the parts of the Stroop Color and Word Test at screening are shown in (Figure 1).

\begin{tabular}{|c|c|c|c|c|c|}
\hline \multirow{2}{*}{$\begin{array}{c}\text { Task and } \\
\text { estimate } \\
\text { parameters }\end{array}$} & \multicolumn{2}{|c|}{$\begin{array}{c}\text { Median value (quartile } \\
\text { range) }\end{array}$} & \multicolumn{3}{|c|}{ Wilcoxon matched-pair test } \\
\cline { 2 - 5 } & Baseline & Week 24 & T & Z & P \\
\hline Part I & $54.0(7.0)$ & $50.0(6.5)$ & 249.5 & 2.6988 & 0.0070 \\
\hline Part II & $63.0(8.0)$ & $57.0(10.5)$ & 271.5 & 2.9389 & 0.0033 \\
\hline Part III & $102.5(8.5)$ & $98.0(4.5)$ & 118 & 4.8206 & 0.0000 \\
\hline $\begin{array}{c}\text { Difference } \\
\text { Part III vs. } \\
\text { Part II }\end{array}$ & $42.0(9.0)$ & $40.0(9.5)$ & 340.5 & 2.185 & 0.0289 \\
\hline $\begin{array}{c}\text { Difference } \\
\text { Part III vs. } \\
\text { Part I }\end{array}$ & $51.5(8.0)$ & $47.0(5.0)$ & 268.0 & 3.132 & 0.0027 \\
\hline $\begin{array}{c}\text { Difference } \\
\text { Part II vs. } \\
\text { Part I }\end{array}$ & $10.0(3.5)$ & $8.0(6.0)$ & 322.5 & 1.817 & 0.069 \\
\hline
\end{tabular}

Table 1: Results (as time in seconds) of the Stroop Color and Word Test at the beginning and end of the study.
The FAB sum-score increased significantly during fluvoxamine therapy, reaching a median value of 18.0 , compared with 17.0 at baseline $(\mathrm{P}<0.001)$. Significant effects were registered in four of the six domains of the FAB $(\mathrm{P}<0.0057)$, with especially marked effects in the areas of inhibitory control and sensitivity to interference (Table 2 and Figure 2).

The median ACE-R sum-score also increased significantly, from 89.5 at baseline to 95.0 at Week $24(\mathrm{P}<0.001)$ with significant $(\mathrm{P} \leq 0.02)$ improvements in every domain except language. In terms of percentage change from baseline, substantially the largest change was seen in the domain of verbal fluency (+27.5\% vs. baseline) (Table 3 and Figure 3 ).

SASS median scores increased from 41.0 at baseline to 44.0 at Week 24 ( $\mathrm{P}=0.001$ by Friedman ANOVA) (Figure 4 ).

HAM-D scores described a consistent downward trajectory throughout the study (Figure 5), with significant $(\mathrm{P}<0.050)$ improvements recorded in 12 of 17 domains. The only domains in which significant improvement was not registered had either zero scores at baseline (suicidal tendencies; feelings of guilt; loss of weight) or a very low score (depressed mood: 0.021 at baseline, 0.000 at Week 24; retardation: 0.063 at baseline, 0.000 at Week 24).

Remission of depression was sustained in all 48 patients who finished the treatment. After adjustment for the two patients who dropped out of the study, the remission rate was $96 \%$.

\section{Safety findings}

A total of 19 adverse events were recorded during the study, mostly at Weeks $2(n=6)$ and $6(n=8)$. All of these adverse events were transient and resolved within 1-2 weeks. No deaths, other serious adverse events or severe adverse events occurred. The most frequent adverse events were drowsiness $(n=9)$ and nausea $(n=3)$. One patient each reported headache, toothache and symptoms of acute respiratory infection. Drowsiness and nausea were considered the only events likely to have any relation with fluvoxamine treatment.

No significant alterations in arterial blood pressure or body weight were noted. Laboratory safety investigations were not performed.

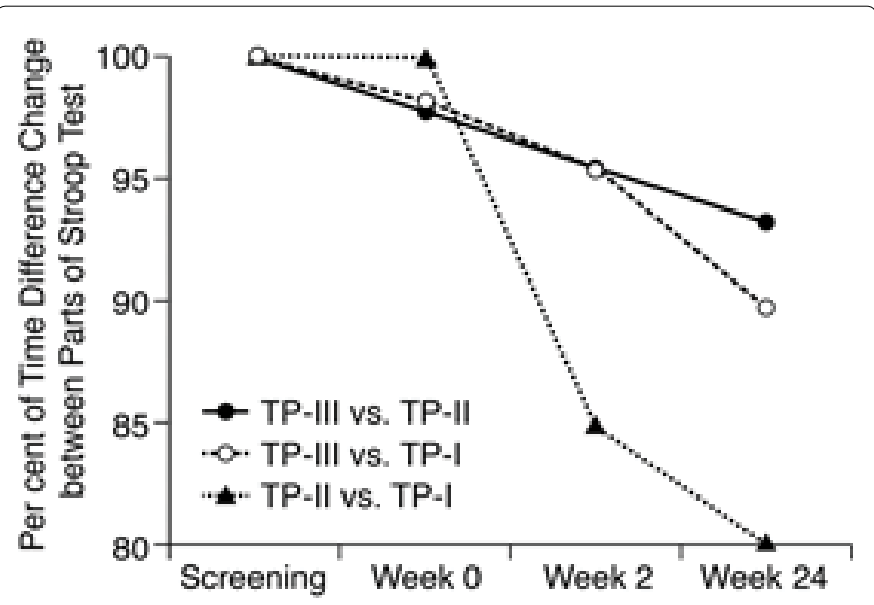

Figure 1: Change in execution time median values of difference (as a percentage from baseline level) between the parts of the Stroop Color and Word Test at screening and during fluvoxamine therapy. TP-I, - II and - III = median time to execute Parts I, II and III of the Stroop Color and Word Test, respectively. 
Citation: Bobrov A, Krasnoslobodtseva L, Mutnykh E (2017) Effects of Fluvoxamine on Cognitive Function in Outpatients with Depression in Remission: Results of an Open-Label Pilot Study. J Psychiatry 20: 417. doi:10.4172/2378-5756.1000417

Page 4 of 6

\begin{tabular}{|c|c|c|c|c|c|c|c|}
\hline \multirow[b]{2}{*}{ Study stage } & \multicolumn{7}{|c|}{ Median value (quartile range) according to $F A B$ subscales } \\
\hline & Sum score & $\begin{array}{l}\text { Conceptualization } \\
\text { (similarities) }\end{array}$ & $\begin{array}{c}\text { Lexical fluency } \\
\text { (mental } \\
\text { flexibility) }\end{array}$ & $\begin{array}{l}\text { Programming } \\
\text { (motor series } \\
\text { "Luria" test) }\end{array}$ & $\begin{array}{l}\text { Sensitivity to } \\
\text { interference } \\
\text { (conflicting } \\
\text { instructions) }\end{array}$ & $\begin{array}{l}\text { Inhibitory } \\
\text { control (go- } \\
\text { no go) }\end{array}$ & $\begin{array}{c}\text { Environmental } \\
\text { autonomy } \\
\text { (prehension } \\
\text { behaviour) }\end{array}$ \\
\hline $\begin{array}{l}\text { Week } 0 \text { (beginning of } \\
\text { treatment) }\end{array}$ & $17.0(2.0)$ & $3.0(0.0)$ & $3.0(0.0)$ & $3.0(0.0)$ & $3.0(1.0)$ & $2.5(1.0)$ & $3.0(0.0)$ \\
\hline Week 2 & $18(1.0)$ & $3(0.0)$ & $3(0.0)$ & $3(0.0)$ & $3(0.5)$ & $3(1.0)$ & $3(0.0)$ \\
\hline Week 24 & $18(0.0)$ & $3(0.0)$ & $3(0.0)$ & $3(0.0)$ & $3(0.0)$ & $3(0.0)$ & $3(0.0)$ \\
\hline P (Friedman ANOVA) & 0.0000 & 0.1353 & 0.0057 & 0.0003 & 0.0000 & 0.0000 & 0.3679 \\
\hline
\end{tabular}

Note: $F A B=F r o n t a l$ Assessment Battery; $A N O V A=a n a l y s i s$ of variance

Table 2: Change in FAB parameters during fluvoxamine treatment.

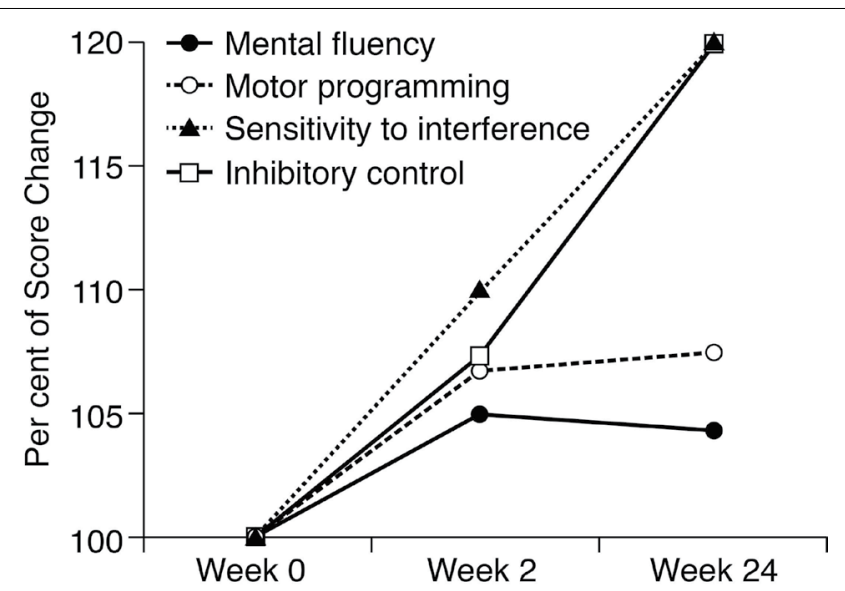

Figure 2: Frontal Assessment Battery domain results for domains with significant changes from baseline (expressed as percentage change from baseline level).

\begin{tabular}{|c|c|c|c|c|c|c|}
\hline \multirow{2}{*}{$\begin{array}{c}\text { Study } \\
\text { stage }\end{array}$} & \multicolumn{5}{|c|}{ Median values (quartile range) according to ACE-R subscales } \\
and sum score \\
\cline { 2 - 8 } & $\begin{array}{c}\text { Attention/ } \\
\text { orientation }\end{array}$ & Memory & $\begin{array}{c}\text { Verbal } \\
\text { fluency }\end{array}$ & Language & $\begin{array}{c}\text { Visuo- } \\
\text { spatial } \\
\text { abilities }\end{array}$ & $\begin{array}{c}\text { Sum } \\
\text { score }\end{array}$ \\
\hline Screening & $15.0(2.5)$ & $25.0(2.0)$ & $9.0(2.5)$ & $26.0(0.0)$ & $14.0(1.5)$ & $89.5(3.5)$ \\
\hline Week 0 & $16.0(2.0)$ & $25.0(1.0)$ & $10.0(2.0)$ & $26.0(0.0)$ & $15.0(2.0)$ & $92.0(5.0)$ \\
\hline Week 2 & $16.0(2.5)$ & $26.0(1.0)$ & $11.0(2.0)$ & $26.0(0.0)$ & $15.0(2.0)$ & $93.5(4.0)$ \\
\hline Week 24 & $17.0(2.5)$ & $26.0(0.5)$ & $12.0(2.0)$ & $26.0(0.0)$ & $15.5(1.0)$ & $95.0(4.0)$ \\
\hline $\begin{array}{c}\text { P } \\
\text { (Friedman } \\
\text { ANOVA) }\end{array}$ & 0.0038 & 0.0231 & 0.0021 & 0.3679 & 0.0004 & 0.0000 \\
\hline
\end{tabular}

Note: ACE-R=revised Addenbrooke's Cognitive Examination; ANOVA=analysis of variance

Table 3: Change in ACE-R parameters at screening and during fluvoxamine treatment.

\section{Discussion}

The results of this pilot study indicate that prophylactic fluvoxamine treatment of patients with remitted depression may be associated with a range of broadly favourable effects on aspects of cognitive function. This preliminary investigation also provides guidance regarding what may be the preferred methods and instruments of a larger trial of fluvoxamine in this situation.

A primary requirement of a larger trial is a control group, in order to compensate for any learning or warming-up effects that may have influenced the performance of the various tests, and to provide more general reference data. The most informative elements of the Stroop

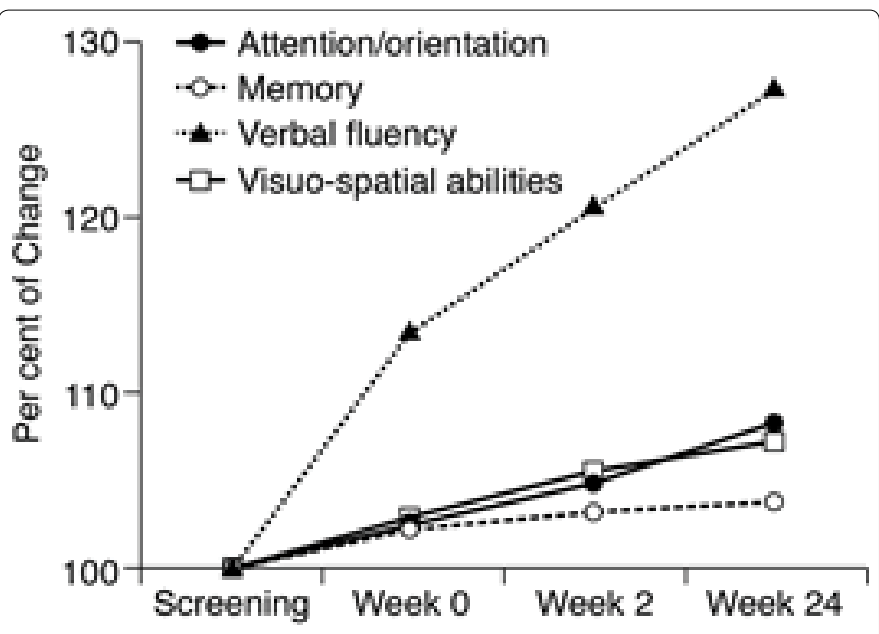

Figure 3: Revised Addenbrooke's Cognitive Examination domain results for domains with significant changes from baseline (expressed as percentage change from screening level).

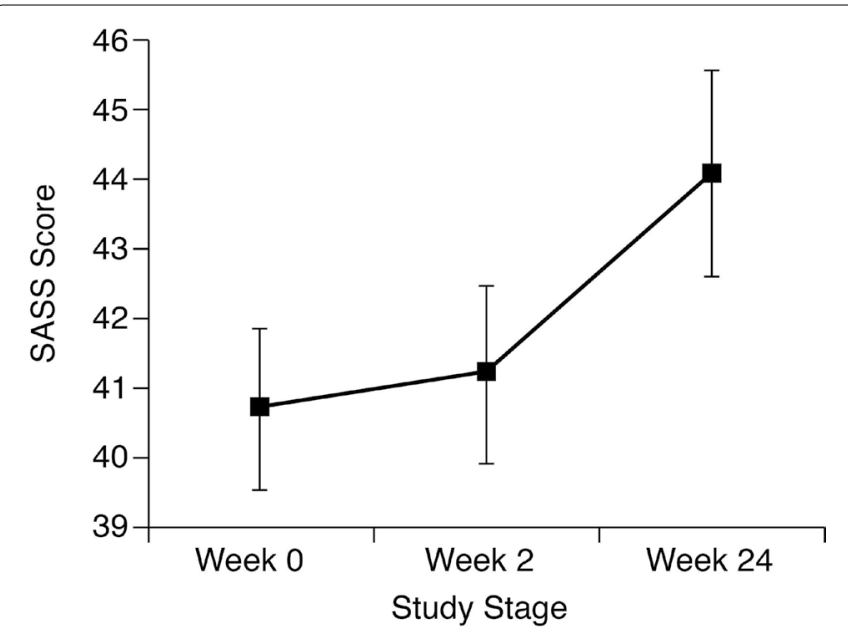

Figure 4: Change in Social Adaptation Self-Evaluation Scale score during treatment with fluvoxamine (mean values $\pm 95 \%$ confidence interval).

Color and Word Test were time spent accomplishing Part III and the difference between the execution times to accomplish Parts I and III and we anticipate using those two indices as the primary endpoints of a future controlled trial. As a secondary endpoint, we consider the most appropriate test to be the ACE-R verbal fluency domain. This nomination reflects the fact that this test aims to assess cognitive changes, which are to a large extent specific for depression. 


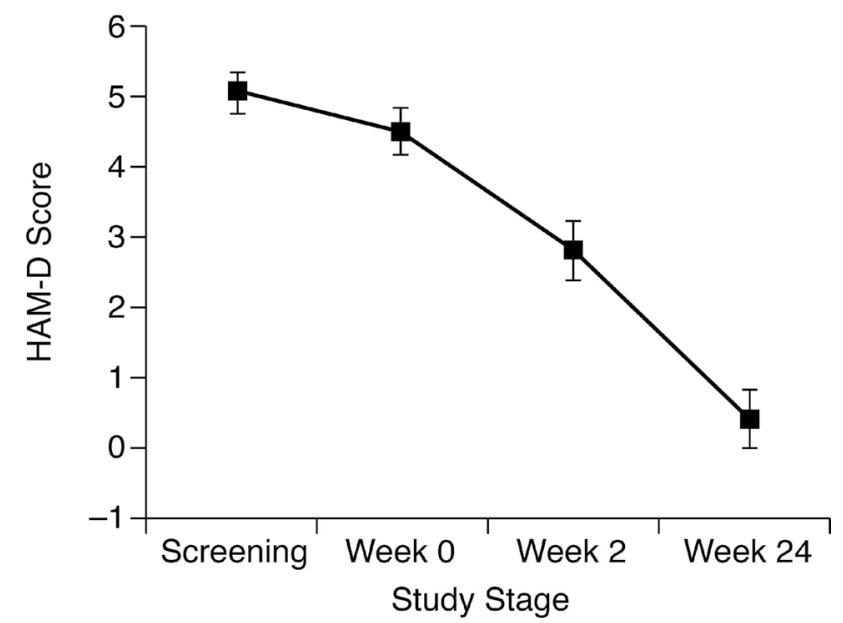

Figure 5: Hamilton Rating Scale for Depression total score changes during treatment with fluvoxamine (mean values $\pm 95 \%$ confidence interval).

By contrast, and notwithstanding significant effects in four of six domains, we conclude from our experience in the present study that it is not useful to assess the conceptualization and environmental autonomy domains of the FAB. These tests are usually used to identify profound brain dysfunction and showed little sensitivity to cognitive changes due to fluvoxamine. Selective use or exclusion of different tests in the FAB could raise questions of methodological validity.

Several additional indices explored in this study could be considered for use as supplementary endpoints in a controlled trial, including the post/pre differences in total ACE-R and SASS scores and the remission rate during the treatment period and subsequently. We would also anticipate studying associations between trends in cognitive tests and a range of HAM-D scores, including the sum score and the specific domains of gastrointestinal symptoms, general somatic symptoms, hypochondriasis and insight, as well as exploring interconnections between cognitive status and insomnia.

Our data indicate that a meaningful therapeutic effect-equivalent to a $>5 \%$ change from baseline in the ACE-R and Part III of the Stroop Color and Word Test-is achievable in between a third and a half of patients. From this, we estimate that a treatment group of approximately 75 patients, plus a group of 40-50 matched controls, would enable us to develop our research in a controlled trial with acceptable statistical power.

We concur with the observation that "Functional recovery after a major depressive episode (MDE) requires both clinical remission and preservation of cognitive skills" [30]. Study of the prevalence and impact of cognitive impairment in relatively young patients with MDD is limited but a detrimental interplay between MDD and cognition is amply documented in older adults: depression may accelerate the conversion to overt cognitive impairment [9], while impaired executive function has been linked to worse responses to treatments for depression [31] and greater costs of depression treatment [13]. Particularly for younger adults with parental and employment responsibilities, executive functioning is probably the most important aspect of cognition. The degree of functional compromise is likely to be smaller than in older patients but the practical impact of even relatively small limitations of executive performance may be significant. Moreover, these functions appear to be the basic psychological instrument underpinning psychical stability and, therefore, decreasing vulnerability to depression.
Functional and structural studies have posited the existence of common pathways linking depression and compromise of executive function and memory to the later development of cognitive impairment $[10,32]$.

Various published studies suggest that use of serotonin-focussed antidepressants (but not tricyclics) can improve executive function and aspects of memory although, in the case of memory, not necessarily to control levels $[16,33,34]$. In one of the largest studies of its kind, the US Health and Retirement Study reported that the long-term rate of decline of cognition in $>13,000$ patients aged $\geq 50$ years was similar in depressed patients taking or not taking antidepressants [15]. Those data, obtained from a very much larger study than ours, are not generally encouraging of a beneficial impact of antidepressant therapy in preserving cognitive function. Our patients were recruited, however, according to specific criteria of recurrent and remitted depression and it is possible, as indicated by our findings, that modest but discernible 'pro-cognitive' benefits may accrue to such patients. Our experience indicates that a larger trial of that possibility is feasible and such a trial is now under consideration.

\section{Conflict of Interest}

The authors declare no conflicts of interest

\section{Acknowledgements}

The authors thank the patients whose willing participation made this study possible. Hughes associates, Oxford, UK, provided editorial assistance in the completion of this report

\section{References}

1. Bortolato B, Carvalho AF, McIntyre RS (2014) Cognitive dysfunction in major depressive disorder: A state-of-the-art clinical review. CNS Neurol Disord Drug Targets 13: 1804-1818

2. Bora E, Harrison BJ, Yücel M, Pantelis C (2013) Cognitive impairment in euthymic major depressive disorder: a meta-analysis. Psychol Med 43: $2017-$ 2026.

3. Mora E, Portella MJ, Forcada I, Vieta E, Mur M (2013) Persistence of cognitive impairment and its negative impact on psychosocial functioning in lithiumtreated, euthymic bipolar patients: A 6-year follow-up study. Psychol Med 43 : 1187-1196.

4. Dlugaj M, Winkler A, Dragano N, Moebus S, Jöckel KH, et al. (2015) Depression and mild cognitive impairment in the general population: results of the Heinz Nixdorf recall study. J Alzheimers Dis 45: 159-174.

5. Ryu SY, Lee SB, Kim TW, Lee TJ (2016) Subjective memory complaints, depressive symptoms and instrumental activities of daily living in mild cognitive impairment. Int Psychogeriatr 28: 487-494.

6. Zahodne LB, Gongvatana A, Cohen RA, Ott BR, Tremont G, et al. (2013) Are apathy and depression independently associated with longitudinal trajectories of cortical atrophy in mild cognitive impairment? Am J Geriatr Psychiatry 21: 1098-1106.

7. Chung JK, Plitman E, Nakajima S, Chakravarty MM, Caravaggio F, et al. (2016) Cortical amyloid $\beta$ deposition and current depressive symptoms in Alzheimer disease and mild cognitive impairment. J Geriatr Psychiatry Neurol 29: 149159.

8. Hohman TJ, Beason-Held LL, Resnick SM (2011) Cognitive complaints, depressive symptoms, and cognitive impairment: are they related? $\mathrm{J} \mathrm{Am}$ Geriatr Soc 59: 1908-1912

9. Dean K, Oulhaj A, Zamboni G, deJager CA, Wilcock GK (2014) Role of depression in predicting time to conversion to mild cognitive impairment. Am J Geriatr Psychiatry 22: 727-734.

10. Duffy SL, Paradise M, Hickie IB, Lewis SJ, Naismith SL, et al. (2014) Cognitive impairment with and without depression history: an analysis of white matter microstructure. J Psychiatry Neurosci 39: 135-143.

11. Diniz BS, Reynolds CF III, Begley A, Dew MA, Anderson SJ, et al. (2014) Brainderived neurotrophic factor levels in late-life depression and comorbid mild cognitive impairment: a longitudinal study. J Psychiatr Res 49: 96-101. 
Citation: Bobrov A, Krasnoslobodtseva L, Mutnykh E (2017) Effects of Fluvoxamine on Cognitive Function in Outpatients with Depression in Remission: Results of an Open-Label Pilot Study. J Psychiatry 20: 417. doi:10.4172/2378-5756.1000417

12. Clark M, DiBenedetti D, Perez V (2016) Cognitive dysfunction and work productivity in major depressive disorder. Expert Rev Pharmacoecon Outcomes Res 16: 455-463.

13. Walker V, Patel H, Kurlander JL, Essoi B, Yang J, et al. (2015) Association between cognitive function and health care costs 3 months and 6 months after initiating antidepressant medication for depressive disorders. J Manag Care Spec Pharm 21: 742-752.

14. Albert U, Brugnoli R, Caraci F, Dell'Osso B, Di Sciascio G, et al. (2016) Italian psychiatrists' perception on cognitive symptoms in major depressive disorder. Int J Psychiatry Clin Pract 20: 2-9.

15. Saczynski JS, Rosen AB, McCammon RJ, Zivin K, Andrade SE, et al. (2015) Antidepressant use and cognitive decline: The health and retirement study. Am J Med 128: 739-746.

16. Nagane A, Baba H, Nakano $Y$, Maeshima H, Hukatsu M, et al. (2014) Comparative study of cognitive impairment between medicated and medicationfree patients with remitted major depression: class-specific influence by tricyclic antidepressants and newer antidepressants. Psychiatry Res 218: 101-105.

17. Daviss WB (2008) A review of co-morbid depression in pediatric ADHD: etiology, phenomenology, and treatment. J Child Adolesc Psychopharmacol 18: $565-571$

18. McIntyre RS, Harrison J, Loft H, Jacobson W, Olsen CK (2016) The effects of vortioxetine on cognitive function in patients with major depressive disorder: A meta-analysis of three randomized controlled trials. Int $\mathrm{J}$ Neuropsychopharmacol.

19. van Waarde $A$, Ramakrishnan NK, Rybczynska AA, Elsinga $\mathrm{PH}$, Ishiwata $\mathrm{K}$ et al. (2011) The cholinergic system, sigma-1 receptors and cognition. Behav Brain Res 221: 543-554.

20. Tadokoro S, Kanahara N, Kikuchi S, Hashimoto K, Masaomi I (2011) Fluvoxamine may prevent onset of psychosis: a case report of a patient at ultra-high risk of psychotic disorder. Ann Gen Psychiatry 10: 26.

21. Hindmarch I, Hashimoto K (2010) Cognition and depression: the effects of fluvoxamine, a sigma-1 receptor agonist, reconsidered. Hum Psychopharmacol 25: $193-200$

22. Furuse T, Hashimoto $K$ (2010) Sigma-1 receptor agonist fluvoxamine for postoperative delirium in older adults: report of three cases. Ann Gen Psychiatry 9: 28 .
23. Lezak MD, Howieson DB, Loring DW (2012) Neuropsychological assessment (5th edn). Oxford University Press, Oxford, UK.

24. Strauss E, Sherman EMS, Spreen O (2006) A compendium of neuropsychological tests: Administration, norms, and commentary (3rd edn), Oxford University Press, New York. pp: 62-63.

25. Mathuranath PS, Nestor PJ, Berrios GE, Rakowicz W, Hodges JR (2000) A brie cognitive test battery to differentiate Alzheimer's disease and frontotempora dementia. Neurology 55: 1613-1620.

26. Hamilton M (1960) A rating scale for depression. J Neurol Neurosurg Psychiatry 23: $56-62$.

27. Dubois B, Slachevsky A, Litvan I, Pillon B (2000) The FAB: A Frontal Assessment Battery at bedside. Neurology 55: 1621-1626.

28. Bosc M, Dubini A, Polin V (1997) Development and validation of a socia functioning scale, the Social Adaptation Self-evaluation Scale. Eur Neuropsychopharmacol 7: S57-S70.

29. Bobrov AE, Krasnoslobodtseva LA, Mutnykh EM, Kursakov AA (2014) Cognitive impairment in depression and potential applications of antidepressants with procognitive effects. Zh Nevrol Psikhiatr Im S S Korsakova 114: 10-14.

30. Cléry-Melin ML, Gorwood P (2017) A simple attention test in the acute phase of a major depressive episode is predictive of later functional remission. Depress Anxiety 34: 159-170.

31. Dawson EL, Caveney AF, Meyers KK, Weisenbach SL, Giordani B, et al. (2017) Executive functioning at baseline prospectively predicts depression treatment response. Prim Care Companion CNS Disord 19

32. Liao W, Zhang X, Shu H, Wang Z, Liu D, et al. (2017) The characteristic of cognitive dysfunction in remitted late life depression and amnestic mild cognitive impairment. Psychiatry Res 251: 168-175.

33. Herrera-Guzmán I, Herrera-Abarca JE, Gudayol-Ferré E, Herrera-Guzmán D, Gómez-Carbajal L, et al. (2010) Effects of selective serotonin reuptake and dual serotonergic-noradrenergic reuptake treatments on attention and executive functions in patients with major depressive disorder. Psychiatry Res 177: $323-329$

34. Gallassi R, Di Sarro R, Morreale A, Amore M (2006) Memory impairment in patients with late-onset major depression: the effect of antidepressant therapy. J Affect Disord 91: 243-250. 